\title{
1 Foraging fidelity and individual specialisation in a temperate bat
}

\section{Myotis Nattereri}

3 Simone Mordue ${ }^{* 1}$, Aileen Mill ${ }^{1}$, Mark Shirley ${ }^{1}$, James Aegerter ${ }^{2}$

$4 \quad{ }^{1}$ Natural and Environmental Sciences, Newcastle University, NE1 7RU

52 National Wildlife Management Centre, Animal and Plant Health Agency (APHA), Sand

6 Hutton, York, YO41 1LZ, United Kingdom

$7 *$ Corresponding author

8 Corresponding authors email: simone.mordue@hotmail.co.uk

9 Abstract

1. Bat populations have declined globally over the last century largely due to anthropogenic change. Many temperate forest species of bat appear loyal to their foraging sites however, conservation of these sites rather than just habitat types is rarely considered and is essential to protect bat populations. It is not clear whether site fidelity in bats is species-specific or a more general trait or why it is exhibited but behaviour patterns could be important for conservation and management objectives. Foraging variation may occur due to 'individual specialisation', such that individuals differ significantly in their prey or habitat utilisation, independent of class-effects. If bats do exhibit individuality in their habitat choice, then protection of 
a mosaic of habitats rather than single preferred habitat per species may be critical to their conservation.

2. The goal here was to determine whether Natterer's bats show fidelity in their foraging choices and whether they show individual specialisation in their foraging habits.

3. Thirty-four individual bats were tracked for at least one full night, from two different sites.

4. Site fidelity in Natterer's was consistent across a range of intervals (months and years) despite contrasting seasonal contexts. Individuals repeatedly exploited specific foraging locations and showed individual specialisation in their habitat use which is consistent with the behaviour of a territorial species.

5. Studies designed to inform conservation and management of temperate bats should attempt to maximize the number of individuals from which movement data is sought, whilst ensuring that data represent a coherent and meaningful measure of behaviour such as a single full night. Bat conservation may need to shift from general descriptions of habitat preferences to considering individual specialisation in habitat use. Designing conservation strategies resilient to environmental change might then advocate protecting a mosaic of habitats to preserve the habitat specialisms of many individuals and enhance their productivity rather than advocating the preservation of a single preferred habitat only suited to a few individuals. 


\section{Introduction}

43 Globally bat populations have declined considerably over the last century largely due to

44 habitat loss, hunting, or disease (1) with recovery predicted to be slow (2). Determining

45 habitat types required for effective conservation of bats can be difficult compared to

46 terrestrial mammals of similar size, due to their ability to fly, which enables them to travel

47 long distances, allowing use of a wide range of resources across a wider variety of habitats.

48 In summer bat roosts and foraging sites can be kilometres apart permitting them to assemble widely dispersed resources they require for survival and reproduction from across extensive landscapes (3).

Flight and the large areas it allows bats to exploit, can also expose individuals to a range of anthropogenic threats such as development (inc. residential, commercial and infrastructure) or sources of mortality such as wind-turbines (4-9) and roads (10-13) on a nightly basis.

These threats can also affect roosts, reduce or degrade available foraging habitat or interfere with the connectivity between habitats (1). Although the conservation of roost sites is important for the maintenance of bat populations e.g. (14), roost provision or the mitigation of roost loss is already common in the management of bat populations. In addition to this, many species use a network of alternative roosts and cope with the loss of a

59 few (15-18). Conversely, bats appear loyal to their foraging sites despite roost loss (17). Hence, the conservation of foraging sites (rather than just habitats) may be as important as roost sites in the conservation of the species, although rarely considered. Further, it is not clear that there are tools to confidently identify the most important foraging areas in the landscape (rather than particular preferred habitat types). This is of some concern especially 
as determining priorities for policy led management of habitats requires a robust understanding.

It is not clear whether site fidelity in bats $(14,19)$ is specific to temperate forest bats, a more general behaviour found in other species or why it is exhibited. Initial work by Egert-Berg et al (20), suggests that many bats may demonstrate a sufficient knowledge of their foraging landscape to choose to repeatedly return to specific productive sites. Male Noctule bats Nyctalus noctula (an aerial hawking species), also show repeated use of the same foraging strategy (foraging trajectories and areas) (21). whilst maximising energy intake, therefore site fidelity may be a way of saving energy in the decision of which habitat to use next (22) e.g. a previously beneficial habitat may have a higher probability of providing sufficient resources than an unexplored new habitat (23). More recently the idea of bats exhibiting site fidelity has been extended to suggest the territorial defence of feeding areas through the use of social calls $(24,25)$. Territorial defence of food resources is thought to minimize feeding competition (26), maximize feeding efficiency through familiarity with the distribution of food resources $(27,28)$ or directly impact reproductive success (29). Site fidelity or territoriality could have significant impacts on conservation and management objectives as well as the tools and measures used to describe bats use of space. Studies to support bat conservation may need to shift from general descriptions of habitat preferences and the assumptions that as long as these are accessible, Favourable

85 Conservation Status can be maintained at specific sites, to considering other aspects of behaviour. Bats like many other mammals may have individual preferences $(30,31)$ and this 
may interact with the emerging study of bat sociality, such that dominant females have preferential access to the best resources (32), maternal inheritance of foraging sites occurs, or bats exhibit territoriality or personality (33) which affects their access to foraging areas. Sexual segregation may also occur with females only utilising more favourable habitats to

91 the exclusion of males who may be found more abundantly in marginal habitats (34).

92 Alternatively, foraging variation may occur due to 'individual specialisation', such that individuals differ significantly in their prey or habitat utilisation, independent of class-effects 94 (35).

Individual specialisation has important evolutionary (35), ecological and management implications as interactions between individuals and environment are not uniform across a

97 landscape (36). If bats do exhibit individuality in their habitat choice, then there may no preferred habitat per species as often asserted by the literature e.g. (37-40) but instead a mosaic of habitats may be critical to their conservation in a changing environment. Therefore, the influence individual expressions of behaviour may have on our understanding of species requirements should be accounted for in measures of resource use and considered in conservation planning and management. choices and the possibility that Natterer's bats in this study show individual specialisation in 
109 Natterer's bats from two sites in Northern England were radio tracked and continuous contact with each bat for full nightly foraging trips was achieved, from dusk to dawn.

111 Foraging site fidelity of individual bats was measured by the degree of spatial overlap of data collected at varying intervals (days, months and years) to determine whether the data

113 collected over a single night has the potential to represent a more substantive and general 114 description of individual behaviour.

\section{Study sites}

116 Natterer's bats (Myotis nattereri) were caught at a roost in a church at Low Catton, East

117 Yorkshire, UK $\left(53.98^{\circ} \mathrm{N}, 0.93^{\circ} \mathrm{W}\right.$ : altitude $\left.15 \mathrm{~m}\right)$ between May and August in 2003 and from

118 woodlands on the Wallington Estate, Northumberland, UK $\left(55.15^{\circ} \mathrm{N}, 1.96^{\circ} \mathrm{W}\right.$ : altitude $160-$

$119200 \mathrm{~m}$ ) between May- September of 2013, 2014 and 2015 (Supplementary 1). Low Catton is

120 a very small rural village in a mixed agricultural landscape typical of lowland England (mainly

121 arable though with some pasture and small scattered parcels of woodland). Wallington

122 Estate is a patchwork of parkland, lakes and woodland, within a mixed pastoral landscape

123 including arable and woodland components as well as open moorland; typical of an upland 124 agricultural landscape in England.

\section{Bat capture and radio-tracking}

126 Bats were captured on an approximately weekly schedule at roosts using a static hand net

127 or harp trap attached to an extendable pole. The frequent roost switching behaviour of the bats at Wallington also required their capture from free flight, using mist nets or harp traps, 
and an acoustic lure. All disturbances at roosts, as well as the capture, handling and

marking of bats were carried out under licence from Natural England (2014-6454-SCI-SCI).

and a full ethical assessment was carried out and approved by the Animal Welfare Ethical

Review Board (AWERB). Captured bats were described noting; sex, age (adult/juvenile),

$134(0.1 \mathrm{~mm}$ ) weight (to $0.1 \mathrm{~g})$ and any existing mark. Unmarked bats were marked with a unique

135 ring (2.9mm Alloy; BCT, England). Selected bats were fitted with radio transmitters (Pip

AG317; Biotrack, Essex, England) attached to the skin between the scapulae using a

137 hypoallergenic dermal adhesive. A small patch of fur was trimmed at the point of

transmitters in one tracking session to ensure that a complete and continuous night of data

141 10days). Forecasts of inclement weather were considered to ensure the timing of tag

142 deployment could always yield robust data.

143 Individual bats were usually radio-tracked by single workers using the close approach

144 method (41) using a Telonics TR-4 receiver (Telonics, Arizona, USA) attached to three-

145 element flexible Yagi antenna or vehicle mounted omni-directional antennae (42). Bats were

146 tracked from their emergence from roosts until their return, with their locations recorded at

14710 minute intervals. 10 minute intervals were selected to prevent temporal correlation

148 between consecutive fixes whilst still recording regular movement patterns (42).

149 Due to the difficulty in obtaining triangulations from fast flying animals (43) especially across

150 undulating terrain such as that of our field site at Wallington, approximate locations of bats

151 were inferred using the strength, direction and variability of signal and recorded onto a

152 large-scale map as polygonal observations. Polygons described an area containing the bat's 
true location later used in determining their foraging cores. The more traditional

description of triangulated points (which uses only the bearing) and subjective estimation of error associated with these were both impractical (co-ordination of observers in difficult

trackers) without necessarily being more objective. Tracking was undertaken in two phases.

access routes and vehicles to ensure a rapid response to unexpected bat movement; though

172 between years. The minimum time between tracking periods was one night. Phase 1

173 tracking often took 2-3 nights (for bats travelling long-distances quickly or those traversing

174 difficult to cross barriers in the landscape such as rivers), and at least one additional night of

175 effort to secure a complete, continuous and uninterrupted night of foraging data. A number

176 of different trackers were used to establish general foraging strategies (phase 1 tracking), 
especially where a number of bats were tagged simultaneously. However, the same tracker

178 (SM at Wallington, JA at Low Catton) undertook all data collection during phase 2 to ensure

179 a consistency in the inference of location and the confidence of its recording. Nights of

180 tracking data with continuous gaps of more than 20 minutes were excluded from the

181 analysis. All roost positions were recorded using a handheld GPS device. Observations were

182 digitised using ArcGIS (v.10.2; ESRI). Subsequent analysis was carried out in R (v. 2.1).

183 Core foraging patches representing areas of high use were described for each complete batnight and used to inform spatial analyses. Observations were transformed into clouds of points by placing a single spatially randomised point into each polygonal description of location. Cores were then identified using a non-parametric clustering approach (clusthr function in adehabitatHR: $95 \%$ inclusion). This was repeated 5 times and the resulting cores were then intersected to find the areas common to all 5 iterations by sorting and overlaying each (gIntersection function in rgeos). These core patches used by bats on any given night represent locations that include the centres of high-density use and the area most exploited for foraging. They also represent the statistical unit in all subsequent analyses.

\section{Data analysis}

\section{Exploring habitat use}

194 Core patches for each individual from the first full night of tracking data collected, were

195 intersected with a land cover layer, LCM2007; (44) to describe the composition of the habitats most used by the bats. To quantify individual specialization using proportion data,

197 Roughgarden's index (45) was used which compares within-individual components of niche width (WIC) to the total niche width exhibited by a population (TNW). Calculations of WIC 
and TNW were carried out in R (RinSp using the 'PSicalc' function(46)). For each individual,

the proportional similarity index $\left(\mathrm{PS}_{\mathrm{i}}\right)$ was calculated following Fodrie et al. (47) based on

habitat deviations in an individual's habitat use relative to population level, average habitat

202

use (approaching $1=$ more generalist; approaching $0=$ more specialised). Mean $\mathrm{PS}_{\mathrm{i}}$ among

203

individuals was used to determine the average amount of specialisation in habitat use

204

across all bats in this study and individuals were deemed to be specialists if their $\mathrm{PS}_{\mathrm{i}}$ value

205

was below the mean population $\mathrm{Ps}_{\mathrm{i}}$ value. Monte Carlo permutations were run with 999

206

replicates to test whether observed WIC/TNW and PS $_{i}$ values differed significantly from a

207

random distribution of values subsampled from the population.

\section{Foraging fidelity}

The potential of a single complete night of radio-tracking data to act as a proxy for the longterm description of an individual's foraging strategy was explored. Pairwise comparisons of foraging area metrics were carried out for all bats including those tracked only once and those tracked repeatedly, either within the calendar year, or between years to describe the similarity of foraging strategies across differing intervals. For each bat the core area was compared between nights and the proportion of area overlap was calculated for each (using the gIntersection function in the rgeos package (48)). This was compared to the proportion of overlap the core area had with every other bat core foraging area. Multiple-response permutation procedure (function MRPP, in the vegan package (49)) analyses were conducted using the Euclidian distance metric and 1,000 iterations with individual proportion overlap as the response variable. To explore whether individual foraging strategies/behaviour measured at varying intervals was repeatable, foraging distance (from roost to the most heavily used core) was compared to foraging schedule (time from 
emergence to arrival at the most heavily used core) across all of the data with observations

package rptR (50), with 1000 permutations) with individual distance and foraging schedules

227 the most used foraging patch was assessed along with the speed at which they travelled

228 there using a linear model (Im) with Distance as the response variable and Speed and Site

229 (Wallington/Low Catton) as the predictors.

\section{Results}

231 Thirty-four individual bats, 17 from Wallington and 17 from Low Catton, were tracked for at

232 least one full night (Additional file 1). Six bats were tracked over repeated years and 24 bats

Table 1). This produced 29 nights of data available for pairwise comparisons of foraging site fidelity at Wallington and 32 nights at Low Catton. There was an average of 32 observations per night (range 16-46) at an average of 20 different foraging patches (range 8-44) resulting in a mean foraging period of 5.3 hours (tracking usually represented most, if not all, of the period of dark at $55^{\circ} \mathrm{N}$ in summer (Table 2)). At Wallington the majority of bats foraged at more than one patch (9/17) although the proportion was slightly lower at Low Catton

241 purposes of this study that all observations carry the same weight. 
242 Table 1. Number of individual bats tracked by site and year used to estimate foraging

243 habitat overlap at two temporal scales, within-year (multiple foraging trips by one bat in

244 one year) and between-year (one bat over multiple years).

\begin{tabular}{|c|c|c|c|}
\hline \multirow[t]{3}{*}{ Site } & \multirow[t]{3}{*}{ Year } & \multicolumn{2}{|c|}{ Bats tracked } \\
\hline & & \multicolumn{2}{|c|}{ Fidelity level } \\
\hline & & Within-year & Between-year \\
\hline Low Catton & 2003 & 17 & No \\
\hline \multirow[t]{3}{*}{ Wallington } & 2013 & 4 & Yes (4) \\
\hline & 2014 & 2 & Yes (4) \\
\hline & 2015 & 1 & Yes (2) \\
\hline
\end{tabular}

245 Between-year fidelity (Yes or No) indicates for which years multi-year animals were

246 tracked with the number of individuals in each of those years in brackets.

247 Table 2 Mean number of Radio tracking observations, patches and foraging time of

248 Natterer's bats tracked at Low Catton and Wallington

\begin{tabular}{llll} 
& Site & Mean & Range \\
\hline Observations & Low Catton & 30 & $16-46$ \\
& Wallington & 34 & $25-41$ \\
& & & $12-44$ \\
& Low Catton & 25 & $8-23$ \\
\hline Patches & Wallington & 14 & \\
\hline (horaging time & Low Catton & 5.0 & $2.66-7.66$ \\
& Wallington & 5.66 & $4.16-6.83$
\end{tabular}


In terms of movement dynamics, the relationship between the distance of the roost of

254 the two $\left(R^{2}=0.217, F_{(3,30)}=4.062, p=0.95\right)$.

255 Figure 1 Distance from roost to core foraging area and speed for bats tracked at

Figure 2 Foraging cores of bats $(n=5)$ tracked repeatedly at Wallington within the same years (2013 - 2015) with 2007 Land cover data and roost locations

Figure 3 Foraging cores of bats tracked repeatedly at Wallington $(n=6)$ between years (2013-2015) with 2007 Land cover data and roost locations year (2003) with 2007 Land cover data

264 At both Wallington and Low Catton, a greater degree of foraging site overlap was observed

265 for individuals tracked multiple times in the same year than between different bats ( 

(range 0.25-0.99)).

Figure 5 The proportion of overlap of $95 \%$ cluster areas for the same bat and different bats within and between years at Wallington and Low Catton. Scores close to 1 indicate $100 \%$ overlap of cluster areas whilst scores close to zero indicate independent use of space

273 There was also a higher degree of spatial overlap for the same bats tracked over different

274 years than for different bats at Wallington (Figure 3, Figure 5; post hoc Tukey tests $\mathrm{P}=0.02$;

275 same bat mean $0.80 \pm 0.03$ (range 0.63-0.96); different bats mean $0.61 \pm 0.01$ (range 0.24-

276 0.97)). Individual bats tracked repeatedly also showed significantly more consistency in

277 their foraging strategy (distance to most used foraging core and time taken to travel to most used foraging core) at both sites than pairwise comparisons with other individuals (Table 3).

significantly higher than random permutations

\begin{tabular}{lll}
\hline & Wallington & Low Catton \\
\hline Distance to most & $0.979^{*} \pm 0.011$ & $0.948^{*} \pm 0.027$ \\
used foraging core & & \\
Time to most used & $0.698^{*} \pm 0.132$ & $0.57^{*} \pm 0.149$ \\
foraging core & & \\
\hline
\end{tabular}




\section{Individual specialisation and habitat use}

283 Overall managed grassland was the most utilised habitat by Natterers at Wallington_(11/17

284 bats had a core are covered by at least $50 \%$ grassland) while arable was most utilised at Low

285 Catton ( $13 / 17$ bats had more than $50 \%$ arable in their core foraging area) (

286 Figure 6). However, there was variability in foraging habitat selection by individuals at both

287 sites, for example the proportion of managed grassland within an individual's core foraging patches at Wallington ranged from $10 \%$ to $98 \%$. The population level measure of individual specialisation (WIC/TNW) suggested that, on average, individual bats used a moderate fraction of the total population niche space (0.63 Wallington, 0.69 Low Catton). Monte Carlo analyses of individual versus population niche variation suggested that bats were more specialised than would be expected by chance at both sites $(P<0.001$ Wallington, $P<0.001$ Low Catton) and some individual bats showed very different use of habitat types to others. At Wallington six bats (H1607, $\mathrm{H} 1608, \mathrm{H} 1609, \mathrm{H} 1679, \mathrm{H} 1680, \mathrm{Y} 2889)$ used unusual habitats or exploited habitats differently to most of the group ( the majority of individuals had large proportions of arable in their core foraging patches (which was the most dominant habitat type in the area) except for four individuals who showed unique habitat use specialisation (Y2049, Y2106, U8558, U3941) and had large areas of unmanaged grassland, managed grassland, coniferous woodland and a mixture of habitat types respectively ( 
Figure 6 Individual variation in habitat use between bats tracked at Wallington_(left) and Low Catton (right). Each individual (x-axis) is represented by a vertical bar, subdivided by the proportion of recordings in each habitat type in relation to the individual's total cluster core area and the specialization index PSi (blue dots; 0 = more specialized; 1 = more generalist) along with the mean colony Psi (dashed line).

\section{Discussion}

Site fidelity in Natterer's bats was consistent across a range of intervals (months and years) despite contrasting seasonal contexts. In addition to this the individuals exploited specific foraging locations and showed individual specialisation in their habitat use which is consistent with the behaviour of a territorial species. Bats also exhibited independent choices between the distance to foraging patch and the speed travelled which suggests the theory of optimal foraging for Natterer's can be rejected.

\section{Foraging fidelity}

Individual foraging fidelity has previously been reported or suggested for a few species of temperate bat $(14,28,51-53)$ albeit with variable strength of evidence. More recently, novel methods have extended the suite of bat species that appear to show this behaviour as well as the quality of observation (egert-berg et al 2018). Here, in common with Kerth et al. 2001 and egert-berg, statistically robust quantitative evidence is provided of the re-use of the same locations and habitats by individuals and here this fidelity appears consistent across a range of intervals (months and years) and extends beyond the immediate period of re-tracking defined by the life of currently available radio-transmitters (typically $<10$ days for small and medium sized species). Fidelity also appears stable, despite contrasting 
seasonal contexts (19). This is potentially good news for bat conservation. Firstly, a reliable

integration of foraging choices into spatially explicit studies of the population dynamics of bats in anthropogenic landscapes.

\section{Territoriality}

334 The behaviour of individuals repeatedly exploiting specific foraging locations whilst also showing individual specialisation in their habitat use is consistent with the behaviour of a

337 fidelity, but all appear to avoid overlap with other tracked bats which is generally considered to reflect territoriality $(53,54)$.

This is not the first time that territoriality has been suggested due to apparent foraging site

340 fidelity in individual bats (53-56), though the difficulties in studying individual bats have

341 previously limited authors' confidence in describing this behaviour. Territoriality has most

342 often been suggested for bat species who have a strong connection with the underlying

343 landscape, and therefore presumably keen to defend a static resource i.e. gleaners or those

344 predating weak flying prey $(57,58)$. For example, the suggestion of territoriality has often

345 been associated with studies of Daubenton's bats foraging over still water e.g. $(14,53)$. For

346 Daubenton's bat, this speculation is supported by their use of a very specific and easy to 
map landscape feature, workers' subsequent confidence in the interpretation of spatial

348 location from radio-tracking and the ability to directly observe foraging behaviour of some

349 individuals. This behaviour includes the repetitive use of space and the presence of social

350 interactions (social calls and chasing) (53). Sociality of temperate bats is becoming widely

351 recognised $(17,18,58-68)$ and the identification of social hierarchies within groups is

352 anticipated (69). Whilst social dominance might only be expressed in the choice of roost (69)

353 or the position within the roosting group, it could also be expressed in other key activity

354 bats undertake e.g. foraging; with dominant individuals choosing and maintaining their

355 preferred locations whilst sub-dominant bats may be left with less productive foraging

356 choices. If social dominance does occur, understanding its effects will be important in the

357 management or conservation of bats where pup production is affected by the quality of the

358 foraging resource (70). In the future workers may need to identify and protect the most

359 productive areas of a landscape and potentially distinguish this from the location of

360 preferred habitats, or those habitats used by inefficient or submissive individuals. It should

361 be noted that only approximately half of each social group under study were tracked and

362 there is no evidence of the functional definition of territory defence i.e. observations of

363 antagonistic behaviour between individuals at potential territory sites.

\section{Behavioural flexibility and individuality}

365 This study agrees with Nachev and York (71) and identifies that individual bats can

366 demonstrate distinct and divergent foraging choices compared to their peers, specifically in

367 their choices of foraging strategy and habitats. In addition, this flexibility in strategy seems

368 to have extended into groups adopting site-specific responses (or traditions) to the 
large use of managed grassland at Wallington compared to the use of arable at Low Catton.

371 Further, our demonstration of foraging site fidelity suggests that these individual differences

372 are likely to be long-lived and may represent either differences in personality (71) or

373 tradition in wildlife species, examples of which are now reported for bats (31) as well as

374 other wildlife $(30,33,72,73)$. Alternatively, individual habitat choice may just represent

375 individual preference in a behaviourally flexible species across the broad menu offered by

376 these mixed landscapes. It should be noted that usually, Natterer's bats are thought to be

377 proficient at both aerial hawking and gleaning $(74,75)$ and might therefore develop almost

378 unconstrained preferences in prey and varied ways to exploit the foraging options available

379 to them.

\section{Conclusions}

381 Effective decision-making for conservation and management relies on strong evidence.

382 Here it is shown that individual bats forage at specific core locations, to which they

383 repeatedly return. Whilst it is easy to simply collate the land-cover or habitat types

384 represented within each core into simplistic descriptions of group behaviour, it is clear that

385 individuals differ greatly and show specialisation in their foraging choices, and that for some

386 common habitats, the choice of core location is unique and important and may not be

387 replaceable at another location, even if the habitat appears the same. Thus studies

388 designed to inform conservation and management of temperate bats should attempt to

389 maximize the number of individuals from which movement data is sought, but ensure that

390 data represent a coherent and meaningful measure of behaviour. Further, it is not clear

391 that any of the specific foraging strategies observed at one site (such as commuting style or 

sensitive to the characters of their landscapes, or the traditions of their communities.

394 Our finding that the strong foraging site fidelity by Natterer's bats and our speculation that this may represent some type of territorial behaviour may off-set some of the effort produce a long-lived and robust description of that bat's behaviour; justifying the additional effort in field-work hours. It may therefore be a better solution in tracking studies to track many individuals for a single night rather than a few individuals for a longer time frame (76).

405 may only suit dominant few individuals.

\section{Declarations}

\section{Ethics approval and consent to participate}

408 All disturbances at roosts, as well as the capture, handling and marking of bats were carried

409 out under licence from Natural England 2014-6454-SCI-SCI.

\section{Consent for publication}

411 Not applicable. 


\section{Availability of data and material}

413 The datasets analysed during the current study are available from the corresponding author

414 on reasonable request.

\section{Competing interests}

416 The authors declare that they have no competing interests

\section{$417 \quad$ Funding}

418 SM and JNA were funded by Defra (SE0430).

\section{Authors' contributions}

420 SM, JA and AM conceived the ideas and designed methodology; SM and JA collected the

421 data; SM and MS analysed data; SM led the writing of the manuscript. All authors

422 contributed critically to the drafts and gave final approval for publication.

\section{Acknowledgements}

424 We thank Jenni MacKay, Daisy Brickhill, Mark Goddard and Phi Wells for help with the radio-

425 tracking at Low Catton and the National Trust at Wallington for access to their site for

426 catching and radio tracking.

\section{References}

428 1. Mickleburgh SP, Hutson AM, Racey PA. A review of the global conservation status of bats. Oryx. 2002;36(01):18-34. 
2. Jones KE, Purvis A, Gittleman JL. Biological correlates of extinction risk in bats. The

American Naturalist. 2003;161(4):601-14.

432 3. Rainho A, Palmeirim JM. The Importance of Distance to Resources in the Spatial

433 Modelling of Bat Foraging Habitat. Plos One. 2011;6(4).

434 4. Zimmerling JR, Francis CM. Bat mortality due to wind turbines in Canada. The Journal 435 of Wildlife Management. 2016.

436 5. Rydell J, Bach L, Dubourg-Savage M-J, Green M, Rodrigues L, Hedenström A. Bat

437 mortality at wind turbines in northwestern Europe. Acta Chiropterologica. 2010;12(2):261-

43874.

439 6. Horn JW, Arnett EB, Kunz TH. Behavioral responses of bats to operating wind

440 turbines. Journal of wildlife management. 2008;72(1):123-32.

441 7. Cryan PM, Barclay RM. Causes of bat fatalities at wind turbines: hypotheses and

442 predictions. Journal of Mammalogy. 2009;90(6):1330-40.

443 8. Baerwald EF, D'Amours GH, Klug BJ, Barclay RM. Barotrauma is a significant cause of 444 bat fatalities at wind turbines. Current biology. 2008;18(16):R695-R6.

445 9. Arnett EB, Baerwald EF, Mathews F, Rodrigues L, Rodríguez-Durán A, Rydell J, et al.

446 Impacts of wind energy development on bats: a global perspective. Bats in the

447 Anthropocene: Conservation of Bats in a Changing World: Springer; 2016. p. 295-323.

448 10. Lesiński G, editor Linear landscape elements and bat casualties on roads-an

449 example. Annales Zoologici Fennici; 2008: BioOne.

450 11. Kitzes J, Merenlender A. Large roads reduce bat activity across multiple species. PloS 451 one. 2014;9(5):e96341.

452 12. Berthinussen A, Altringham J. Do bat gantries and underpasses help bats cross roads safely? PloS one. 2012;7(6):e38775. 
13. Altringham J, Kerth G. Bats and roads. Bats in the Anthropocene: Conservation of

Bats in a Changing World: Springer; 2016. p. 35-62.

14. Kapfer G, Rigot T, Holsbeek L, Aron S. Roost and hunting site fidelity of female and

457 juvenile Daubenton's bat Myotis daubentonii (Kuhl, 1817)(Chiroptera: Vespertilionidae).

458 Mammalian Biology-Zeitschrift für Säugetierkunde. 2008;73(4):267-75.

459

15. Rhodes M, Wardell-Johnson GW, Rhodes MP, Raymond B. Applying network analysis

460 to the conservation of habitat trees in urban environments: a case study from Brisbane,

461 Australia. Conservation Biology. 2006;20(3):861-70.

462 16. Johnson JS, Kropczynski JN, Lacki MJ, Langlois GD. Social networks of Rafinesque's

463 big-eared bats (Corynorhinus rafinesquii) in bottomland hardwood forests. Journal of

464 Mammalogy. 2012;93(6):1545-58.

465 17. Silvis A, Ford W, Britzke E. Effects of Hierarchical Roost Removal on Northern Long-

466 Eared Bat (Myotis septentrionalis) Maternity Colonies. Plos One. 2015;10(1).

467 18. August TA, Nunn MA, Fensome AG, Linton DM, Mathews F. Sympatric Woodland

468 Myotis Bats Form Tight-Knit Social Groups with Exclusive Roost Home Ranges. PloS one.

$469 \quad 2014 ; 9(10): \mathrm{e} 112225$.

470 19. Hillen J, Kiefer A, Veith M. Interannual fidelity to roosting habitat and flight paths by

471 female western barbastelle bats. Acta Chiropterologica. 2010;12(1):187-95.

472 20. Egert-Berg K, Hurme ER, Greif S, Goldstein A, Harten L, Flores-Martínez JJ, et al.

473 Resource ephemerality drives social foraging in bats. Current Biology. 2018;28(22):3667-73.

474 21. Roeleke M, Blohm T, Kramer-Schadt S, Yovel Y, Voigt CC. Habitat use of bats in

475 relation to wind turbines revealed by GPS tracking. Scientific reports. 2016;6:28961. 
476

477

478

479

480

481

482

483

484

485

486

487

488

489

490

491

492

493

494

495

496

497

498

22. Arthur B, Hindell M, Bester M, Trathan P, Jonsen I, Staniland I, et al. Return

Customers: Foraging Site Fidelity and the Effect of Environmental Variability in Wide-

Ranging Antarctic Fur Seals. PloS one. 2015;10(3):e0120888.

23. Call KA, Ream RR, Johnson D, Sterling JT, Towell RG. Foraging route tactics and site fidelity of adult female northern fur seal (Callorhinus ursinus) around the Pribilof Islands.

Deep Sea Research Part II: Topical Studies in Oceanography. 2008;55(16):1883-96.

24. Luo B, Lu G, Chen K, Guo D, Huang X, Liu Y, et al. Social calls honestly signal female competitive ability in Asian particoloured bats. Animal Behaviour. 2017;127:101-8.

25. Gadziola MA, Grimsley JM, Faure PA, Wenstrup JJ. Social vocalizations of big brown bats vary with behavioral context. PLoS One. 2012;7(9):e44550.

26. Wrangham R. On the evolution of ape social systems. Information (International Social Science Council). 1979;18(3):336-68.

27. Pusey A, Williams J, Goodall J. The influence of dominance rank on the reproductive success of female chimpanzees. Science. 1997;277(5327):828-31.

28. Hillen J, Kiefer A, Veith M. Foraging site fidelity shapes the spatial organisation of a population of female western barbastelle bats. Biological Conservation. 2009;142(4):817-23.

29. Thompson ME, Kahlenberg SM, Gilby IC, Wrangham RW. Core area quality is associated with variance in reproductive success among female chimpanzees at Kibale National Park. Animal Behaviour. 2007;73(3):501-12.

30. Araújo MS, Bolnick DI, Layman CA. The ecological causes of individual specialisation. Ecology Letters. 2011;14(9):948-58.

31. Cryan PM, Stricker CA, Wunder MB. Evidence of cryptic individual specialization in an opportunistic insectivorous bat. Journal of Mammalogy. 2012;93(2):381-9. 
32. Honer $\mathrm{O}$, Wachter B, Hofer $\mathrm{H}$, Wilhelm $\mathrm{K}$, Thierer D, Trillmich F, et al. The fitness of

500 dispersing spotted hyaena sons is influenced by maternal social status. Nature

501 Communications. 2010;1.

502 33. Patrick S, Weimerskirch H. Personality, Foraging and Fitness Consequences in a Long

503 Lived Seabird. Plos One. 2014;9(2).

504 34. Angell RL, Butlin RK, Altringham JD. Sexual segregation and flexible mating patterns

505 in temperate bats. PloS one. 2013;8(1):e54194.

506 35. Bolnick DI, Yang LH, Fordyce JA, Davis JM, Svanbäck R. Measuring individual-level

507 resource specialization. Ecology. 2002;83(10):2936-41.

508 36. Thiemann GW, Iverson SJ, Stirling I, Obbard ME. Individual patterns of prey selection

509 and dietary specialization in an Arctic marine carnivore. Oikos. 2011;120(10):1469-78.

510 37. Catto CMC, Hutson AM, Racey PA, Stephenson PJ. Foraging behaviour and habitat

511 use of the serotine bat (Eptesicus serotinus) in southern England. Journal of Zoology.

512 1996;238:623-33.

513 38. Robinson M, Stebbings R. Home range and habitat use by the serotine bat, Eptesicus

514 serotinus, in England. Journal of Zoology. 1997;243(1):117-36.

515 39. Arlettaz R. Habitat selection as a major resource partitioning mechanism between

516 the two sympatric sibling bat species Myotis myotis and Myotis blythii. Journal of Animal

517 Ecology. 1999;68(3):460-71.

518 40. Russo D, Jones G, Migliozzi A. Habitat selection by the Mediterranean horseshoe bat,

519 Rhinolophus euryale (Chiroptera: Rhinolophidae) in a rural area of southern Italy and

520 implications for conservation. Biological Conservation. 2002;107(1):71-81.

521 41. White GC, Garrott RA. Analysis of wildlife radio-tracking data: Elsevier; 1990. 
522

523

524

525

526

527

528

529

530

531

532

533

534

535

536

537

538

539

540

541

542

543

544

545

42. Kenward R. A manual for wildlife radio tagging. London: London : Academic Press;

2001.

43. Mackie IJ, Racey PA. Habitat use varies with reproductive state in noctule bats

(Nyctalus noctula): implications for conservation. Biological Conservation. 2007;140(1):70-7.

44. Morton D, Rowland, C., Wood, C., Meek, L., Marston, C., SMith, G., Simpson, I.C.

Final report for LCM2007- the new land cover map. CS Technical Report No 11/07.

NERC/Centre for Ecology \& Hydrology; 2011. Contract No.: CEH project number. C03259.

45. Roughgarden J. Evolution of niche width. 1972.

46. Zaccarelli N, Bolnick DI, Mancinelli G. RInSp: an r package for the analysis of individual specialization in resource use. Methods in Ecology and Evolution. 2013;4(11):1018-23.

47. Fodrie FJ, Yeager LA, Grabowski JH, Layman CA, Sherwood GD, Kenworthy MD. Measuring individuality in habitat use across complex landscapes: approaches, constraints, and implications for assessing resource specialization. Oecologia. 2015;178(1):75-87.

48. Bivand R, Rundel C, Pebesma E, Stuetz R, Hufthammer KO, Giraudoux P, et al. Package 'rgeos'. R package v 03-24. 2018.

49. Oksanen J, Blanchet FG, Kindt R, Legendre P, Minchin PR, O'hara RB, et al. Package 'vegan'. Community ecology package, version. 2013;2(9).

50. Stoffel MA, Nakagawa S, Schielzeth H. rptR: Repeatability estimation and variance decomposition by generalized linear mixed-effects models. Methods in Ecology and Evolution. 2017;8(11):1639-44.

51. Kerth G, Wagner M, Konig B. Roosting together, foraging apart: information transfer about food is unlikely to explain sociality in female Bechstein's bats (Myotis bechsteini). Behavioral Ecology and Sociobiology. 2001;50(3):283-91. 
546 52. Siemers BM, Kaipf I, Schnitzler HU. The use of day roosts and foraging grounds by

547 Natterer's bats (Myotis nattereri Kuhl, 1818) from a colony in southern Germany.

548 International Journal of Mammalian Biology. 1999;64:241-5.

549 53. Encarnação JA, Becker NI, Ekschmitt K. When do Daubenton's bats (Myotis

550 daubentonii) fly far for dinner? Canadian Journal of Zoology. 2010;88(12):1192-201.

551 54. Chaverri G, Gamba-Rios M, Kunz T. Range overlap and association patterns in the

552 tent-making bat Artibeus watsoni. Animal Behaviour. 2007;73:157-64.

$55355 . \quad$ Rydell J. Feeding territoriality in female northern bats, Eptesicus nilssoni. Ethology.

$554 \quad 1986 ; 72(4): 329-37$.

555 56. Rossiter SJ, Jones G, Ransome RD, Barratt EM. Relatedness structure and kin-biased

556 foraging in the greater horseshoe bat (Rhinolophus ferrumequinum). Behavioral Ecology

557 and Sociobiology. 2002;51(6):510-8.

558 57. Reyes-Garcia V, McDade TW, Molina JL, Leonard WR, Tanner SN, Huanca T, et al.

559 Social rank and adult male nutritional status: Evidence of the social gradient in health from a

560 foraging-farming society. Social Science \& Medicine. 2008;67(12):2107-15.

561 58. Gerell R, Lundberg K. Social organization in the bat Pipistrellus pipistrellus.

562 Behavioral Ecology and Sociobiology. 1985;16(2):177-84.

563 59. Silvis A, Kniowski AB, Gehrt SD, Ford WM. Roosting and Foraging Social Structure of

564 the Endangered Indiana Bat (Myotis sodalis). PloS one. 2014;9(5):e96937.

565 60. Siemers BM, Kerth G. Do echolocation calls of wild colony-living Bechstein's bats

566 (Myotis bechsteinii) provide individual-specific signatures? Behavioral Ecology and

567 Sociobiology. 2006;59(3):443-54. 
61. Patriquin KJ, Leonard ML, Broders HG, Garroway CJ. Do social networks of female

Sociobiology. 2010;64(6):899-913.

571 62. Park KJ, Masters E, Altringham JD. Social structure of three sympatric bat species. J

572 Zool, Lond. 1998;244:379-89.

573 63. Kerth G, Perony N, Schweitzer F. Bats are able to maintain long-term social

574 relationships despite the high fission-fusion dynamics of their groups. Proc Biol Sci. 2011;278(1719):2761-7.

64. Kashima K, Ohtsuki H, Satake A. Fission-fusion bat behavior as a strategy for balancing the conflicting needs of maximizing information accuracy and minimizing infection risk. J Theor Biol. 2013;318:101-9.

65. Johnson JS, Kropczynski JN, Lacki MJ. Social network analysis and the study of

580 sociality in bats. Acta Chiropterologica. 2013;15(1):1-17.

66. Entwistle A, Racey P, Speakman J. Social and population structure of a gleaning bat,

582 Plecotus auritus. Journal of Zoology. 2000;252(1):11-7.

583 67. August TA. The Social Structure, Ecology and Pathogens of Bats in the UK. 2012.

584 68. Altringham JD, Senior P. Social systems and ecology of bats. Sexual segregation in

585 vertebrates (KE Ruckstuhl and P Neuhaus, eds) Cambridge University Press, Cambridge,

586 United Kingdom. 2005:280-302.

587 69. Fleischmann D, Kerth G. Roosting behavior and group decision making in 2 syntopic 588 bat species with fission-fusion societies. Behavioral Ecology. 2014;25(5):1240-7.

589 70. Arlettaz R, Christe P, Schaub M. Food availability as a major driver in the evolution of 590 life-history strategies of sibling species. Ecology and Evolution. 2017. 
71. Nachev V, Winter Y. Behavioral repeatability and choice performance in wild free-

flying nectarivorous bats (Glossophaga commissarisi). Behavioral Ecology and Sociobiology.

593 $2019 ; 73(2): 24$

594

72. Knudsen R, Primicerio R, Amundsen P, Klemetsen A. Temporal stability of individual

595 feeding specialization may promote speciation. Journal of Animal Ecology. 2010;79(1):161-8.

596 73. Robertson A, McDonald RA, Delahay RJ, Kelly SD, Bearhop S. Individual foraging

597 specialisation in a social mammal: the European badger (Meles meles). Oecologia.

598 2014;176(2):409-21.

599

74. Swift SM, Racey PA. Gleaning as a foraging strategy in Natterer's bat Myotis

600 nattereri. Behav Ecol Sociobiol. 2002;52:408-16.

601

75. Siemers BA, Schnitzler HU. Natterer's bat hawks for prey close to vegetation using

602 echolocation signals of very broad bandwidth. Behav Ecol Sociobiol. 2000;47:400-12.

76. Wakefield ED, Cleasby IR, Bearhop S, Bodey TW, Davies RD, Miller PI, et al.

604 Long-term individual foraging site fidelity-why some gannets don't change their spots.

605 Ecology. 2015;96(11):3058-74.

606 77. Aebischer NJ, Robertson PA, Kenward RE. Compositional analysis of habitat use from 607 animal radio-tracking data. Ecology. 1993;74(5):1313-25.

608 78. Manly B, McDonald L, Thomas D, McDonald TL, Erickson WP. Resource selection by 609 animals: statistical design and analysis for field studies: Springer Science \& Business Media; 6102007.

\section{Additional files}

\section{Additional file 1.doc}




\section{3 "Biometric data of bats tracked"}

614 Sex, body mass, reproductive condition, tracking date and number of recordings and

615 locations of bats tracked in this study.

616 
- Wallington $\bullet$ Low Catton

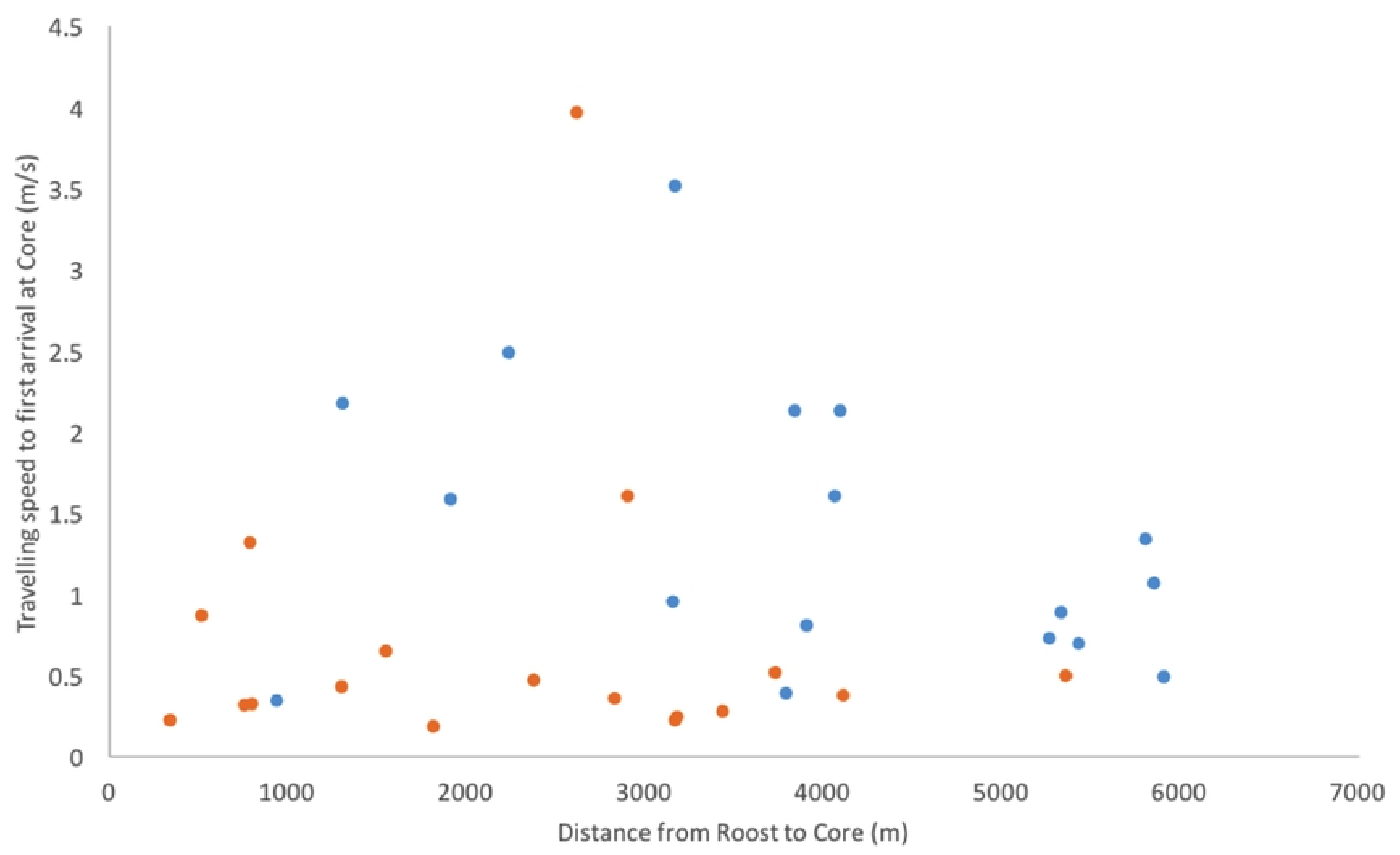

fig 1 


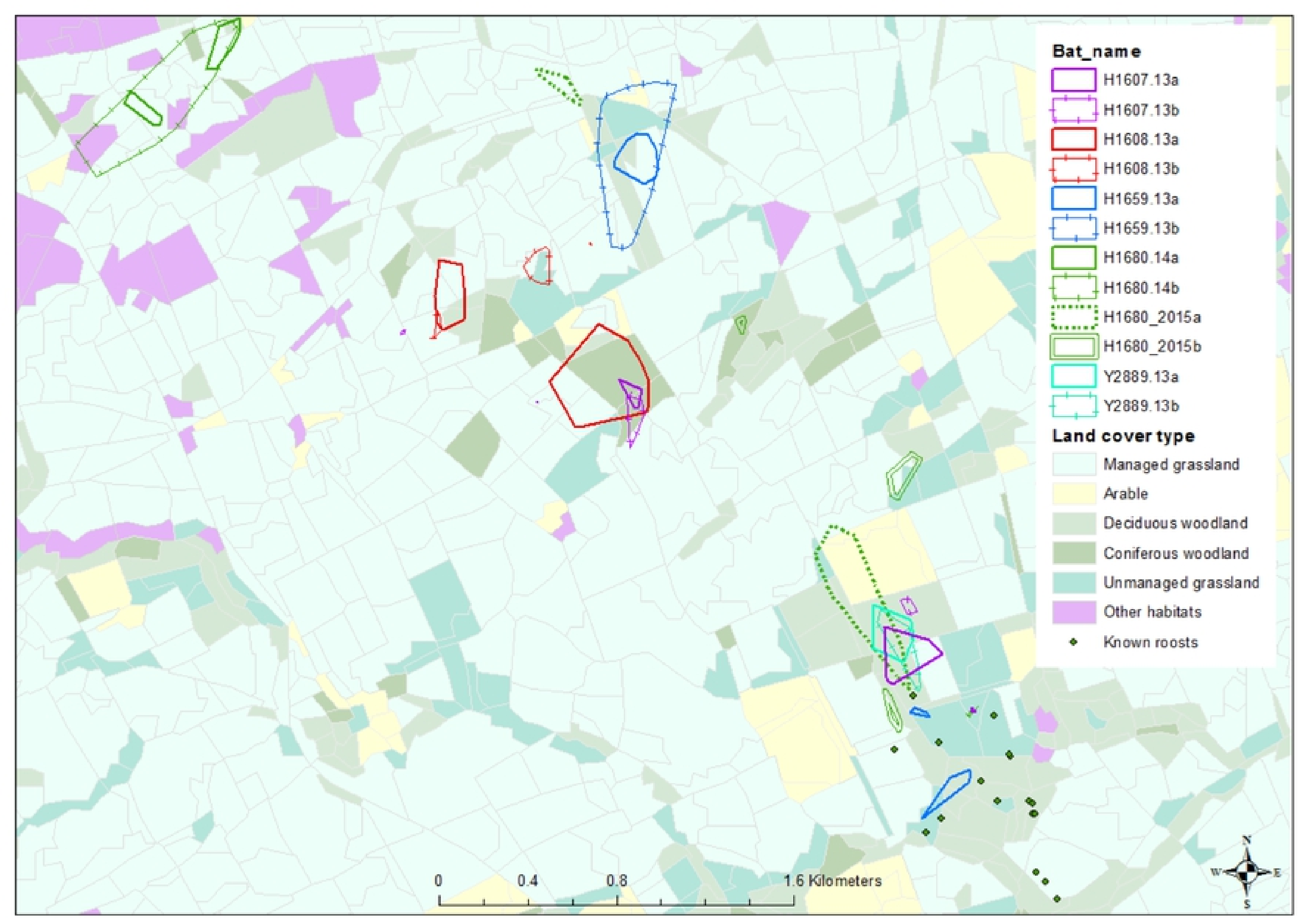

fig 2 


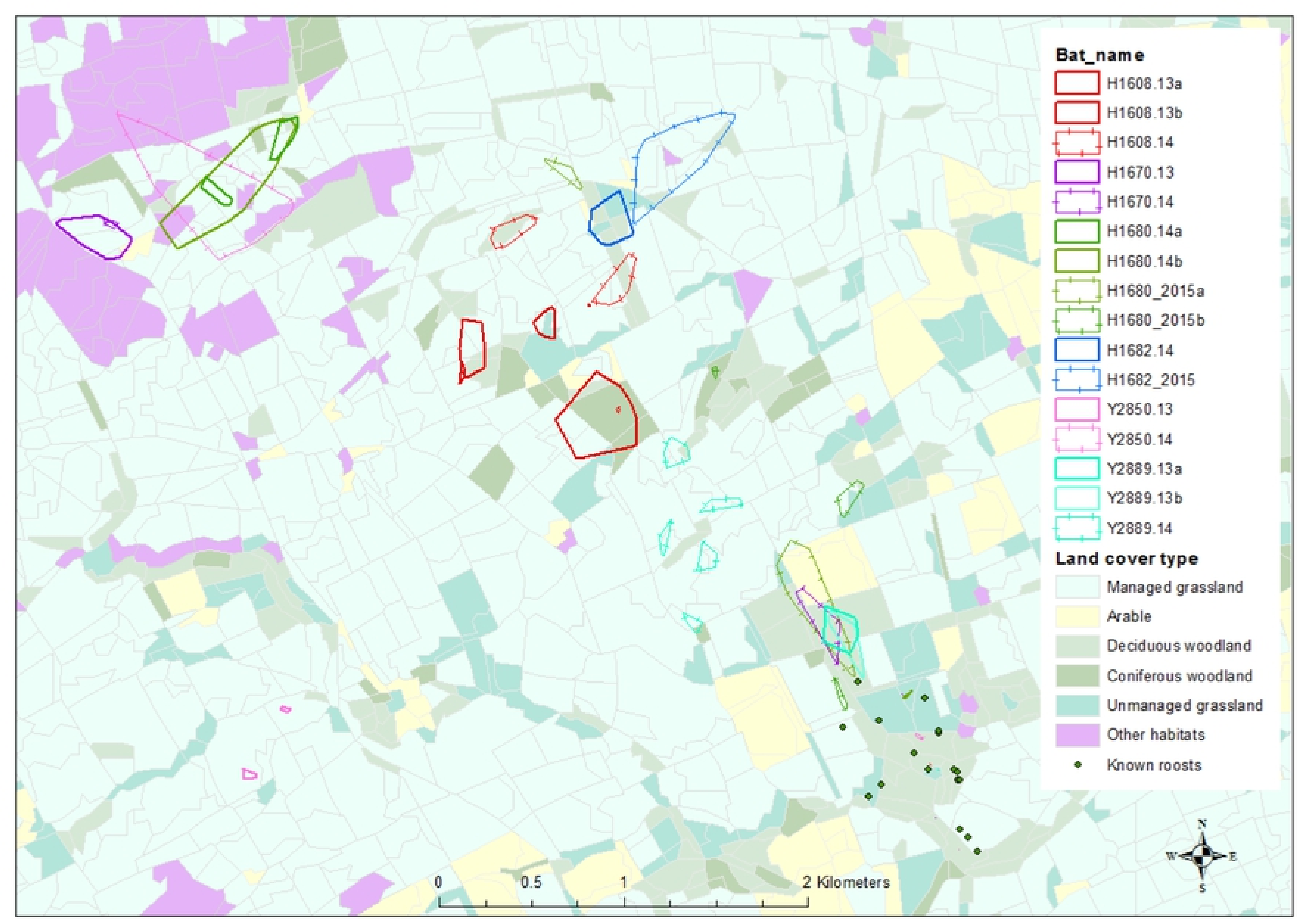

fig 3 


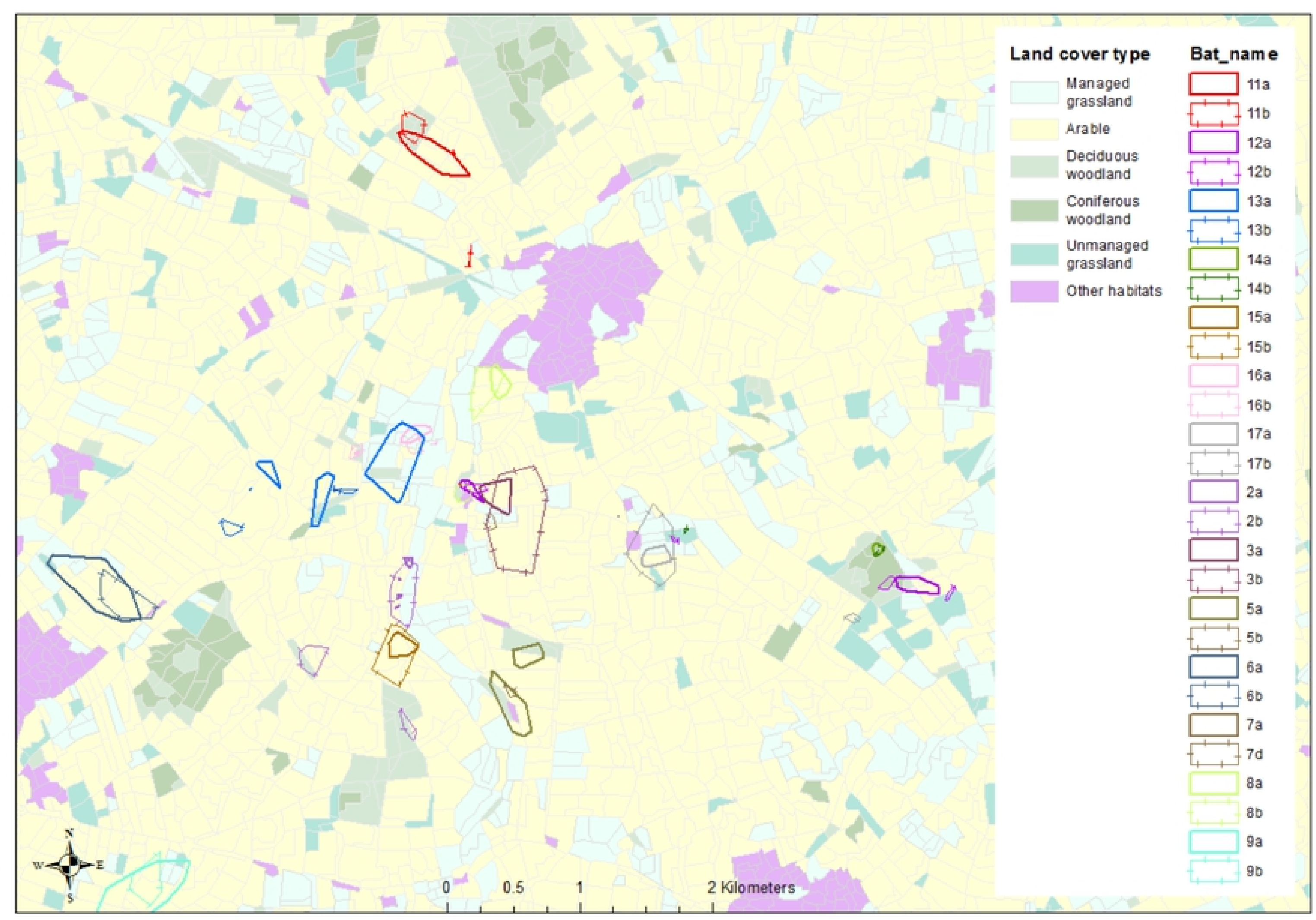

fig 4 
bioRxiv preprint doi: https://doi.org/10.1101/713750; this version posted July 25, 2019. The copyright holder for this preprint (which was not certified by peer review) is the author/funder, who has granted bioRxiv a license to display the preprint in perpetuity. It is made
available under aCC-BY 4.0 International license.
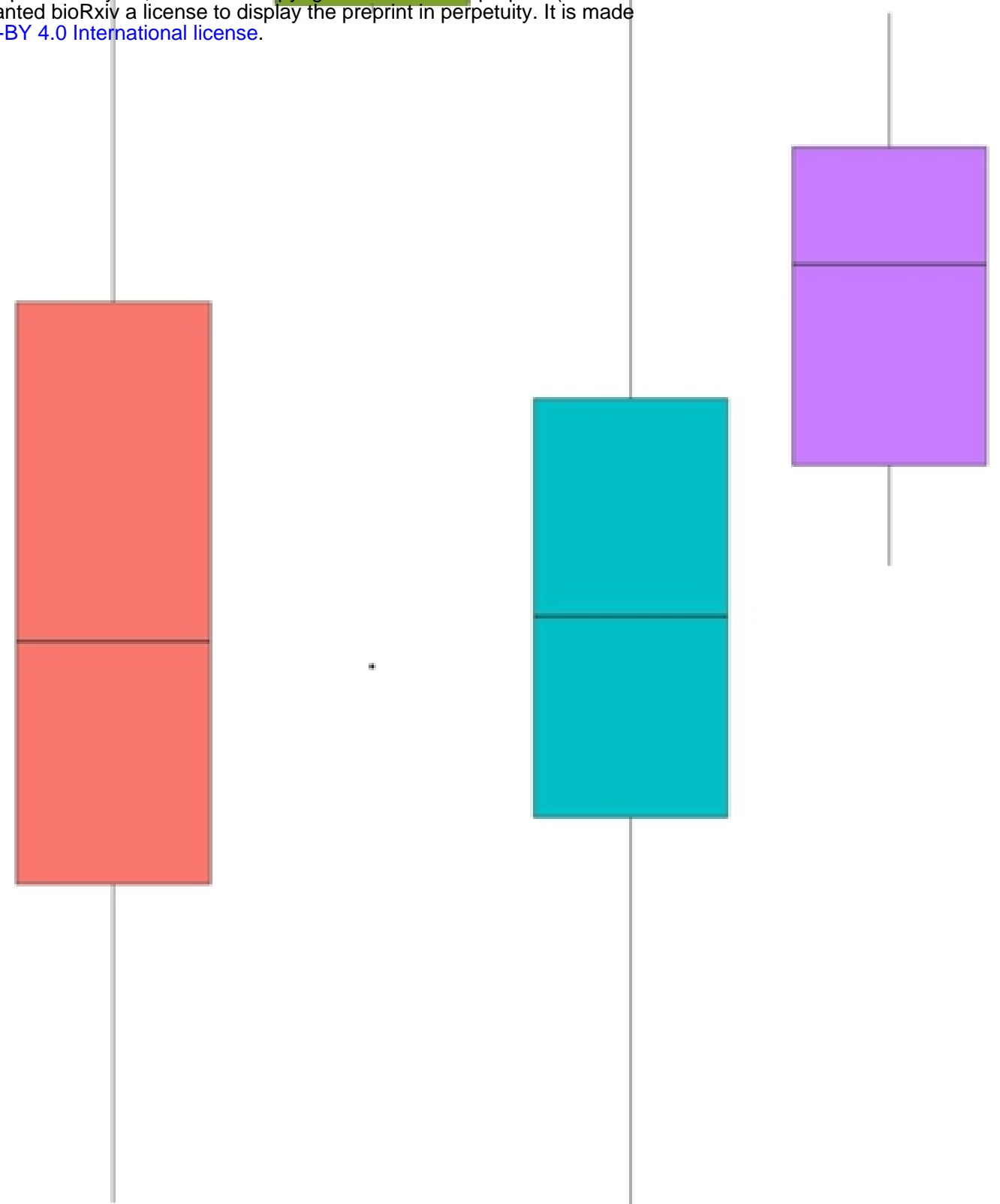

0.2
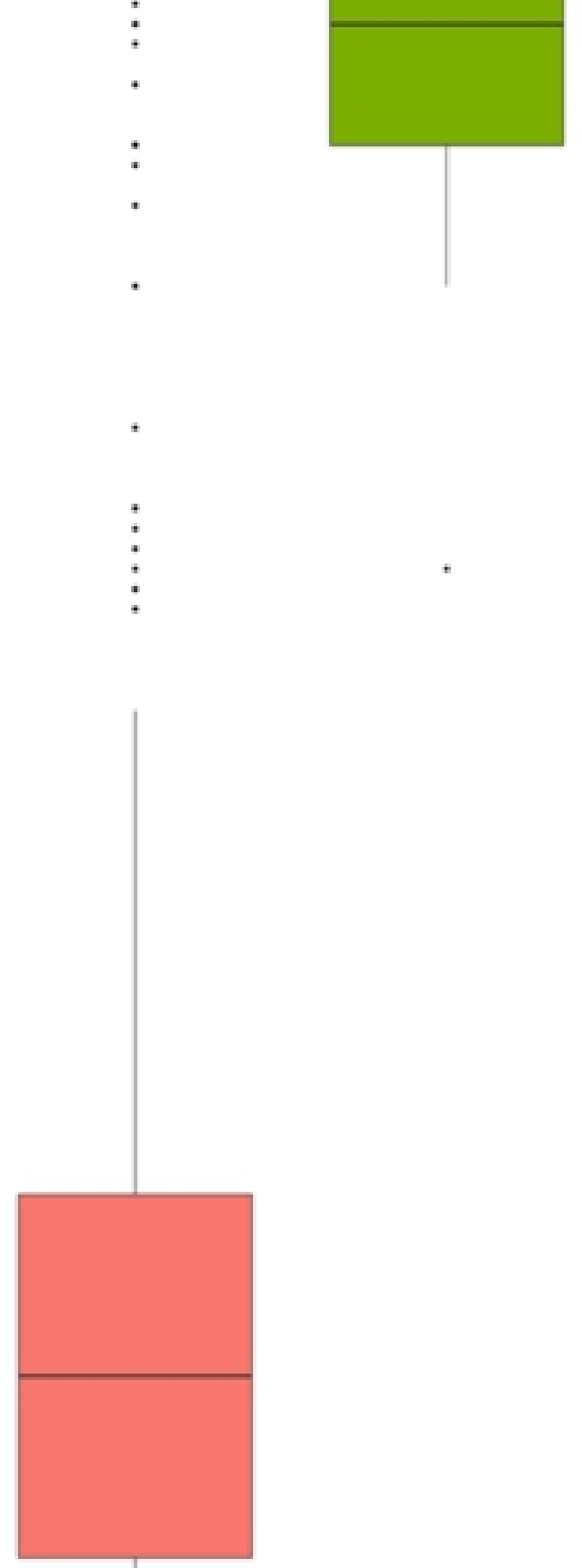

0.4

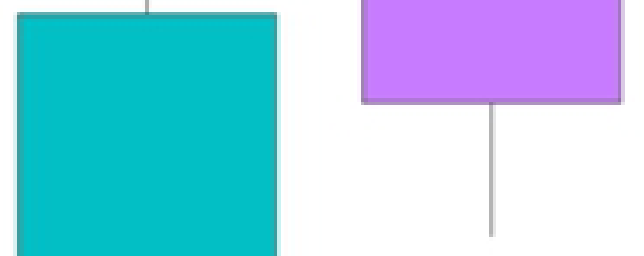


